\title{
UN ENFOQUE FENOMENOLÓGICO Y SISTÉMICO DE LA ECONOMÍA POLÍTICA GLOBAL
}

\section{A PHENOMENOLOGICAL AND SYSTEMIC APPROACH TO THE GLOBAL POLITICAL ECONOMY}

Dr. Antonio Hidalgo (alhc@uhu.es). Universidad de Huelva (Huelva, España)

\begin{abstract}
In this article we present an application from the phenomenological perspective of knowledge and the selforganised system theory to the field of the Global Political Economy, which allows us to give a theory didactical view of the functioning and regulation of the current global economy.
\end{abstract}

Key words: phenomenology, economy, political, global, system

\section{Resumen}

En este artículo presentamos la aplicación de la perspectiva fenomenológica del conocimiento y de la teoría de sistemas autoorganizados en el ámbito de la Economía Política Global, que nos permite dar una visión teórica didáctica del funcionamiento y la regulación de la actual economía mundial.

Palabras clave: fenomenología, economía, política, global, sistemas

\section{La fenomenología como perspectiva epistemológica}

El conocimiento científico como conocimiento de la realidad suele abordarse desde tres perspectivas epistemológicas: el representacionismo, el constructivismo y la fenomenología.

El representacionismo parte de la idea de que la realidad está en el objeto y que el sujeto al observar lo que hace es representar de manera fidedigna esta realidad; por tanto, la realidad sería una realidad objetiva, es decir, vendría determinada por el objeto y el sujeto no puede modificar dicha realidad en el proceso de observación y representación de la misma.

El constructivismo parte de la idea de que la realidad está en el sujeto que al pensar sobre un objeto construye una realidad; por tanto, la realidad sería una realidad subjetiva; es decir, vendría determinada por el sujeto, siendo el objeto sólo la excusa del pensamiento del sujeto en el proceso de construcción de la realidad. 
La fenomenología estaría a mitad de camino entre el representacionismo radical y el constructivismo radical y parte de la idea de que el sujeto por medio del proceso de percepción del objeto hace surgir la realidad; por tanto, la realidad sería una realidad percibida, que no podría existir sin la interacción entre el objeto y el sujeto. Así pues, la realidad ni es representada, ni es construida por el sujeto, sino que es percibida por éste.

Así, un acontecimiento que no es percibido (ni en su acontecer, ni en sus consecuencias) por ningún sujeto, desde la perspectiva fenomenológica del conocimiento científico no existiría. Un ejemplo de ello podría ser la extinción de una especie de ser vivo en un pasado remoto del que no hubiese quedado ningún resto fósil; dicha extinción no sería una realidad.

También podríamos decir que un acontecimiento pensado por un sujeto que no se derive directamente de un proceso de percepción, desde la perspectiva fenomenológica del conocimiento científico, tampoco existiría. Un ejemplo de ello podría ser un sueño o una fantasía; dicho sueño o fantasía no sería una realidad.

Ahora bien, cuando el sujeto observa un acontecimiento objetivo, lo percibe por medio de los sentidos, y de dicha percepción surge un fenómeno; fenómeno que no sería el acontecimiento objetivo en sí, ya que éste tendría dimensiones que no pueden ser captadas en el proceso de percepción, sino que sería el acontecimiento objetivo percibido por el sujeto. Un ejemplo de ello podría ser el fenómeno de la vida, ya que la vida puede ser percibida y sería, por tanto, una realidad; sin embargo, podría haber dimensiones del acontecimiento de la vida, como el alma, que al no poder ser percibidas no formarían parte de la realidad.

Partiendo, por tanto, de una perspectiva fenomenológica, nos acercaremos al conocimiento científico por medio del estudio de los fenómenos.

\section{Los fenómenos, los sistemas, las organizaciones y las estructuras sociales}

Dado que la Economía es una Ciencia Social, de todos los fenómenos que podríamos estudiar, a nosotros nos interesan especialmente los que se producen por la interacción entre los seres humanos; a dichos fenómenos los denominamos fenómenos sociales y al conjunto de éstos lo denominamos ámbito de los fenómenos sociales.

En el ámbito de los fenómenos sociales cualquier sujeto en su proceso de percepción puede hacer una distinción, es decir, señalar una unidad haciendo una operación que define sus límites y la separa de su trasfondo. Esta operación de distinción es subjetiva y viene determinada, en un principio, por la experiencia perceptiva del sujeto; así, dos sujetos con experiencias perceptivas diferentes podrían hacer distinciones diferentes (1).

Sin embargo, para distinguir una unidad en el ámbito de los fenómenos sociales es necesario que el sujeto acuda al proceso de percepción con una idea del tipo de organización que pretende percibir; entendiendo por organización las relaciones entre los componentes que definen una unidad. La idea de organización procedería de la propia experiencia perceptiva del sujeto (experiencia perceptiva individual), o bien de la experiencia perceptiva que le han transmito otros sujetos (experiencia perceptiva colectiva).

Así pues, si una unidad es percibida por un sujeto en un proceso de distinción a partir de una idea previa de las relaciones entre los componentes que la definen como unidad, dicha unidad sería un conjunto de 
componentes interactivos; y a un conjunto de componentes interactivos que puede percibirse como una unidad se denomina sistema.

En una operación de distinción, un sistema social llegaría hasta donde el sujeto es capaz de percibir que se encuentran sus límites, siendo todo lo demás su trasfondo; y dichos límites estarían donde el sujeto deja de percibir los componentes y el tipo de relaciones que han servido para definir la unidad.

Antes de continuar debemos hacer algunas aclaraciones respecto a los conceptos de sistema, organización y estructura. Ya hemos visto que el término sistema lo podemos definir como un complejo de componentes interactivos que puede considerarse como una sola entidad y que el término organización está referido a las relaciones entre los componentes que definen un sistema como una unidad. Por su parte, el término estructura se refiere a los componentes concretos y a las relaciones concretas que se dan entre ellos y que permiten la perfección del sistema como tal entidad; así, la estructura de un sistema determina el espacio en que dicho sistema existe, lo que permitiría la distinción de varios sistemas sociales iguales, con la misma organización social, pero espacialmente separados y con estructuras sociales diferentes.

Sin embargo, no todos los fenómenos sociales son de la misma naturaleza y cabría hacer divisiones en el ámbito de los mismos para crear subconjunto o ámbitos menores.

\section{Los fenómenos, los sistemas, las organizaciones y las estructuras económicas}

A nosotros nos interesa estudiar un tipo determinado de fenómenos sociales, que son aquellos que se producen por las interacciones entre seres humanos basadas en actividades vinculadas con la producción, el intercambio y el consumo de bienes y servicios susceptibles de satisfacer las necesidades de los seres humanos, así como en actividades de distribución de la renta derivadas de las anteriores. A dicho tipo de relaciones las denominamos relaciones económicas (2), que serían las que darían lugar a los fenómenos económicos, los cuales, colectivamente, formarían el ámbito de los fenómenos económicos como subconjunto del ámbito de los fenómenos sociales.

Por tanto, siguiendo el procedimiento explicado anteriormente, para distinguir un sistema económico en el ámbito de los fenómenos económicos vamos a necesitar una idea del tipo de relaciones económicas que mantiene los seres humanos, es decir, una idea de organización económica que nos permita definir los límites de dicho sistema. A partir de aquí, podríamos proceder a distinguir un tipo determinado de sistema económico, o varios sistemas económicos con la misma organización, pero separados espacialmente y con distintas estructuras económicas.

\subsection{Los tipos de organización económica}

La experiencia perceptiva colectiva de quienes se han dedicado al estudio de los sistemas económicos ha permitido conformar cinco tipos ideales de organización económica, cada uno de los cuales caracterizado por un tipo diferente de relaciones económicas; dichos tipos de organización económica serían: el comunismo primitivo (por ejemplo, en algunas sociedades indígenas aisladas de la Amazonía); el tributarismo (3) (por ejemplo, en el Imperio Inca); el esclavismo (por ejemplo, en el Imperio Romano); el feudalismo (por ejemplo, en la Francia de la Edad Media); el mercantilismo (por ejemplo, en la España del Renacimiento); el capitalismo (por ejemplo, en el Reino Unido desde la Revolución Industrial) y el socialismo (por ejemplo, en la URSS). 
Estos tipos ideales no siempre han sido útiles para distinguir todo tipo de sistemas económicos, dado que algunos sujetos a lo largo de la historia han percibido relaciones económicas que no se correspondían completamente con ninguno de estos tipos de organización, pero parcialmente con un par de ellos; así surgirían formas de organización híbridas como el capitalismo esclavista (que se dio, por ejemplo, en los Estados del Sur de EEUU antes de la Guerra de Secesión), el feudo-capitalismo (que se dio, por ejemplo, en Japón hasta la Segunda Guerra Mundial), el mercantil-socialismo (que se dio, por ejemplo, en China tras la muerte de Mao) o el capitalismo de Estado (que se dio, por ejemplo, en la Alemania nazi).

\section{Cuadro 1}

\section{Características principales de los tipos de organización económica}

\begin{tabular}{|c|c|c|c|c|}
\hline $\begin{array}{c}\text { Tipo de } \\
\text { organización }\end{array}$ & Producción & Factor Tierra & Factor Capital & Factor Trabajo \\
\hline $\begin{array}{c}\text { Comunismo } \\
\text { Primitivo }\end{array}$ & $\begin{array}{l}\text { Distribuida } \\
\text { comunalmente } \\
\text { según necesidades }\end{array}$ & $\begin{array}{l}\text { Propiedad pública } \\
\text { comunal }\end{array}$ & $\begin{array}{l}\text { Propiedad pública } \\
\text { comunal }\end{array}$ & $\begin{array}{l}\text { Propiedad del } \\
\text { trabajador con } \\
\text { obligación comunal }\end{array}$ \\
\hline Tributarismo & $\begin{array}{l}\text { Distribuida por } \\
\text { comunalmente y } \\
\text { por el sistema } \\
\text { tributario }\end{array}$ & $\begin{array}{l}\text { Propiedad pública } \\
\text { comunal }\end{array}$ & $\begin{array}{l}\text { Propiedad pública } \\
\text { comunal }\end{array}$ & $\begin{array}{l}\text { Propiedad del } \\
\text { trabajador con } \\
\text { obligación comunal }\end{array}$ \\
\hline Esclavismo & $\begin{array}{l}\text { Distribuida por el } \\
\text { mercado según } \\
\text { oferta y demanda y } \\
\text { por el sistema } \\
\text { tributario }\end{array}$ & $\begin{array}{l}\text { Propiedad privada } \\
\text { concentrada por el } \\
\text { amo }\end{array}$ & $\begin{array}{l}\text { Propiedad privada } \\
\text { concentrada por el } \\
\text { amo }\end{array}$ & $\begin{array}{l}\text { Posesión del } \\
\text { esclavo que es } \\
\text { propiedad privada } \\
\text { del amo }\end{array}$ \\
\hline Feudalismo & $\begin{array}{l}\text { Distribuida por el } \\
\text { sistema tributario } \\
\text { feudal }\end{array}$ & $\begin{array}{l}\text { Posesión } \\
\text { concentrada en } \\
\text { feudos por el señor } \\
\text { feudal } \\
\text { (inseparables tierra } \\
\text { y trabajo) }\end{array}$ & $\begin{array}{l}\text { Posesión } \\
\text { concentrada por el } \\
\text { señor feudal }\end{array}$ & $\begin{array}{l}\text { Posesión del señor } \\
\text { del feudo donde } \\
\text { vive el siervo } \\
\text { (inseparables tierra } \\
\text { y trabajo) }\end{array}$ \\
\hline Mercantilismo & $\begin{array}{l}\text { Distribución por el } \\
\text { mercado según } \\
\text { oferta y demanda y } \\
\text { por el sistema } \\
\text { tributario }\end{array}$ & $\begin{array}{l}\text { Propiedad privada } \\
\text { del campesino o el } \\
\text { terrateniente }\end{array}$ & $\begin{array}{l}\text { Propiedad privada } \\
\text { del trabajador }\end{array}$ & $\begin{array}{l}\text { Propiedad del } \\
\text { trabajador }\end{array}$ \\
\hline Capitalismo & $\begin{array}{l}\text { Distribuida por el } \\
\text { mercado según }\end{array}$ & $\begin{array}{l}\text { Propiedad privada } \\
\text { del campesino o el }\end{array}$ & $\begin{array}{l}\text { Propiedad privada } \\
\text { del capitalista }\end{array}$ & $\begin{array}{l}\text { Propiedad del } \\
\text { trabajador }\end{array}$ \\
\hline
\end{tabular}




\begin{tabular}{|c|l|l|l|l|}
\hline & $\begin{array}{l}\text { oferta y demanda y } \\
\text { por el sistema } \\
\text { tributario }\end{array}$ & terrateniente & & \\
\hline Socialismo & $\begin{array}{l}\text { Distribuida por el } \\
\text { Estado mediante la } \\
\text { planificación según } \\
\text { necesidades }\end{array}$ & $\begin{array}{l}\text { Propiedad pública } \\
\text { estatal }\end{array}$ & $\begin{array}{l}\text { Propiedad pública } \\
\text { estatal }\end{array}$ & $\begin{array}{l}\text { Propiedad del } \\
\text { trabajador con } \\
\text { obligación estatal } \\
\text { según capacidades }\end{array}$ \\
\hline
\end{tabular}

Fuente: Elaboración propia.

En el Cuadro 1 se caracterizan los siete tipos organización antes citados en función del mecanismo de distribución de la producción de bienes y servicios y de la propiedad de los tres principales factores de producción (la tierra, el capital y el trabajo) (4). De entre todos ellos, el tipo de organización que nos interesa por ser la más común en la actualidad es el capitalismo.

\subsection{El capitalismo como organización económica}

El capitalismo es aquel tipo de organización económica caracterizado porque las relaciones que se dan entre seres humanos, en relación con la producción, el intercambio y el consumo de bienes y servicios y con la distribución de la renta derivada de las mismas, se realizan por medio del mercado. Y el mercado es aquella institución (5) a través de la cual los productores y los consumidores oferentes de un determinado bien, servicio o factor, entran en estrecha relación comercial a fin de realizar abundantes transacciones y bajo estas condiciones establecer el precio del mismo.

El mercado se rige por la ley de la oferta y la demanda, según la cual cuando un bien, servicio o factor se hiciese abundante, provocaría una disminución de su precio, mientras que cuando el mismo se hiciese escaso, provocaría un aumento de dicho precio.

Atendiendo al objeto del intercambio, podemos distinguir cuatro tipos de mercados: el mercado de bienes y servicios; el mercado del factor tierra; el mercado del factor capital; y el mercado del factor trabajo. En el caso del mercado de bienes y servicios, el precio que surge de la interacción de oferta y demanda sirve como indicador tanto para los productores, que aumentarían la producción de dicho bien o servicio si subiese el precio y la reducirían si bajase, como para los consumidores, que aumentarían su consumo de dicho bien o servicio si bajase el precio y lo reducirían si subiese.

Por lo que se refiere a los mercados de factores el comportamiento sería similar; ante una bajada del precio de un factor productivo, sus propietarios reducirían su oferta y los productores aumentarían su demanda; mientras que ante una subida del precio de dicho factor productivo, sus propietarios aumentarían su oferta y los productores reducirían su demanda. Conviene recordar que los precios de los factores reciben unos nombres particulares; así la renta es el precio de la tierra, el interés es el precio del capital y el salario es el precio del trabajo. 
Tanto los mercados de bienes y servicios como los mercados de la tierra y el capital están amparados por el derecho de propiedad privada. Dicho derecho sería otra de las instituciones del capitalismo y consistiría en la capacidad de disponer de un determinado bien, un determinado servicio, una determinada tierra o un determinado capital, de manera exclusiva sin más limitaciones que las que impongan las leyes; dicha capacidad de disposición incluiría la posibilidad de enajenación.

En el mercado de trabajo, por su parte, no existiría la propiedad privada como tal, en tanto que el factor trabajo es inseparable del trabajador; así, éste sólo puede vender su factor, a cambio de un salario, cediendo la disposición de su tiempo al productor para que lo emplee en la forma que estime conveniente en el proceso productivo sin más limitaciones que las que impongan las leyes y el contrato de trabajo.

En síntesis, podríamos definir las relaciones económicas capitalistas como aquellas relaciones económicas basadas en el mercado, en el que se intercambian de manera más o menos libre tanto bienes y servicios como factores productivos.

\subsection{La distinción del sistema económico capitalista casi-mundial}

Teniendo en cuenta todo lo anterior, en el ámbito de los fenómenos económicos y partiendo de la idea de organización económica capitalista, podríamos realizar una operación de distinción para identificar una unidad o sistema económico capitalista, definiendo los límites de éste y separándolo de su trasfondo o entorno.

Así pues, si observamos las relaciones económicas capitalistas, podemos percibir que los seres humanos mantenemos dichas relaciones con otros seres humanos de ubicaciones geográficas cercanas y remotas; es decir, dichas relaciones se dan a lo largo y ancho de casi todo el planeta y tan sólo quedarían al margen de las mismas ciertas sociedades indígenas aisladas y ciertos países socialistas relativamente autárquicos, donde las relaciones económicas serían de diferente naturaleza.

Por tanto, en el ámbito de los fenómenos económicos, podemos distinguir una entidad casi-mundial compuesta de seres humanos que mantienen relaciones capitalistas, a diferencia de otros grupos minoritarios de seres humanos cuyas relaciones económicas no son de naturaleza capitalista. A dicha entidad la denominaremos sistema económico capitalista casi-mundial.

De esta forma, lo que define al sistema económico capitalista casi-mundial como sistema es su organización capitalista, en la medida en que le da sentido y permite distinguirlo. Mientras lo que permite catalogar al actual sistema económico capitalista como sistema económico capitalista casi-mundial es su estructura, es decir, que sus componentes concretos estén repartidos por casi todo el planeta y que las interrelaciones concretas entre ellos se den por casi toda la geografía mundial.

El hecho de que las relaciones económicas capitalistas se den como un todo continuo a lo largo y ancho de casi todo el planeta, nos permite distinguir un único sistema económico capitalista con una única estructura económica y no varios sistemas económicos capitalistas diferentes con diferentes estructuras económicas.

Pero para que una entidad sea considerada como sistema es preciso que reúna una serie de condiciones, ya que, según la definición clásica, un sistema es un complejo de componentes interactivos que puede considerarse como una sola entidad. Por tanto, el sistema económico capitalista casi-mundial es tal sistema, 
en la medida en que es un conjunto de seres humanos con interrelaciones económicas capitalistas que colectivamente pueden ser considerados como una unidad.

3.4. La distinción de otros sistemas económicos en el entorno del sistema económico capitalista casi-mundial

En línea con lo anterior, en la operación de distinción del sistema económico capitalista casi-mundial, realizamos implícitamente una delimitación de la frontera de dicho sistema. Cuando incluimos dentro del sistema económico capitalista casi-mundial a todos los seres humanos que mantienen relaciones económicas de corte capitalista y a dichas relaciones, dejamos fuera a una serie de seres humanos que poseen relaciones económicas de naturaleza no capitalista y a dichas relaciones; estos seres humanos con sus relaciones ocupan un espacio físico que denominamos entorno.

El espacio físico que observamos en una operación de distinción, denominado ambiente, podemos dividirlo en nicho, o espacio físico que ocupa el sistema, y entorno, o espacio físico que no ocupa el sistema. Desde esta perspectiva, el nicho del sistema económico capitalista casi-mundial sería casi todo el planeta, mientras que el entorno sería aquel espacio físico donde no se dan relaciones capitalistas entre seres humanos.

Así, el entorno del sistema económico capitalista casi-mundial lo constituye el espacio físico donde no habitan seres humanos (principalmente la mayor parte de los océanos, desiertos y zonas polares (6) o donde los seres humanos mantienen relaciones económicas no capitalistas, como es el caso de ciertas sociedades indígenas (Amazonía, África Central...) y los residuales países de socialismo real autárquico (Corea del Norte y, parcialmente, Cuba).

Como es lógico, en el entorno también pueden realizarse operaciones de distinción tratando de identificar sistemas económicos de organización no capitalista. Así, si observamos dicho entorno guiados perceptivamente por formas de organización como el comunismo primitivo o el socialismo, podemos distinguir diversos sistemas económicos comunitarios locales y sistemas económicos socialistas nacionales (7).

\subsection{Hacia un verdadero sistema económico mundial}

En el caso de las relaciones entre el sistema económico capitalista casi-mundial y los sistemas económicos comunitarios locales, éstas son escasas por el propio aislamiento físico de dichos sistemas. Sin embargo, a medida que las relaciones de éstos con aquél se van haciendo más intensas, dicho contacto termina provocando una serie de cambios en los sistemas económicos comunitarios locales que, en muchos casos, les conducen a una pérdida de identidad, a su desintegración como sistemas y a la absorción de sus elementos por parte del sistema económico capitalista casi-mundial.

Esto es lo que ha ocurrido históricamente a medida que los seres humanos de distintos sistemas económicos capitalistas nacionales comenzaron a mantener relaciones económicas con seres humanos de sociedades indígenas aisladas (sistemas económicos comunitarios locales); el contacto entre individuos de sistemas tan distintos, habitualmente promovido por individuos pertenecientes a sistemas económicos capitalistas nacionales por razones económicas (caza, explotación minera, cultivo de tierras, comercio...), terminó generando serios problemas al interior de dichas comunidades (anomia, alcoholismo...) que, en muchos 
casos, condujeron a su desaparición como tales comunidades y a su integración en el sistema económico capitalista nacional con el que mantuvieron el contacto.

En el caso de las relaciones entre el sistema económico capitalista casi-mundial con los sistemas económicos socialistas nacionales sucede algo parecido; el aumento de las relaciones de éstos con el sistema económico capitalista casi-mundial tiende a provocar la pérdida de identidad de los mismos (sería el caso, por ejemplo, de los efectos de las inversiones extranjeras y del turismo en Cuba) y es muy probable que en el futuro sean absorbidos por aquél, desintegrándose como sistemas (al igual que les sucedió a los sistemas económicos socialistas nacionales de la Europa Central y Oriental).

A medida que el sistema económico capitalista casi-mundial vaya absorbiendo a los diferentes componentes de los sistemas económicos de su entorno, dicho entorno se irá reduciendo al tiempo que el nicho de aquél se irá ampliando, hasta que dicho nicho coincida con el medio, a excepción de las zonas deshabitadas, y todas las relaciones económicas entre seres humanos sean de naturaleza capitalista e internas al citado sistema. Sólo en ese momento podríamos hablar con propiedad de la existencia de un sistema económico capitalista mundial.

No obstante, teniendo todo esto claro, y al objeto de simplificar, dado el carácter marginal de los sistemas económicos del citado entorno, podríamos referimos al sistema económico capitalista casi-mundial como sistema económico capitalista mundial; y de manera aún más resumida, por entender que todas las relaciones económicas relevantes son de naturaleza capitalista, podríamos referirnos a dicho sistema como sistema económico mundial.

Resumiendo, desde una perspectiva fenomenológica, la economía mundial puede ser estudiada como un sistema económico mundial.

\section{La gobernanza global neoliberal como regulación de la economía mundial}

Antes de que el proceso de globalización diese como resultado la aparición del sistema económico mundial, los sistemas económicos capitalistas nacionales que ahora lo integran eran sistemas autónomos, es decir, eran sistemas con capacidad para autorregularse, siendo los mecanismos de regulación una parte de los propios sistemas; y de todos los mecanismos que contribuían a la regulación de los sistemas económicos capitalistas nacionales, los más importantes eran, sin duda, los gobiernos nacionales.

Sin embargo, con la integración de los sistemas económicos capitalistas nacionales en el sistema económico mundial, aquéllos han ido perdiendo autonomía en la medida en que los gobiernos nacionales han ido perdiendo, a su vez, capacidad para regularlos; lo cual se debe al hecho de que dicha capacidad ha sido transferida hacia mecanismos de regulación transnacionales durante el proceso de globalización.

Pero, a diferencia de los sistemas económicos capitalistas nacionales, entre los mecanismos de regulación del sistema económico mundial no existe ninguno que tenga una capacidad de regulación sobre este sistema similar a la que tenían los gobiernos nacionales sobre los sistemas económicos capitalistas nacionales; es decir, no existe un gobierno mundial. No obstante, ello no significa que no existan otros mecanismos que permitan la regulación del sistema económico mundial.

De hecho la regulación del sistema económico mundial, aún con esta peculiaridad de ausencia de gobierno, 
es muy similar a la de cualquier sistema económico autónomo e incluso a la de cualquier sistema social que goce de autonomía.

\subsection{La regulación de los sistemas sociales autónomos}

La regulación de un sistema social autónomo, o autorregulación de un sistema social, consiste en la permanente neutralización de las perturbaciones que sacuden a dicho sistema procedentes del exterior del mismo (de su ambiente o de su entorno) o de su propio interior (de los seres humanos).

Tanto este último tipo de perturbaciones como la regulación misma del sistema nos conducen al concepto de agente (o actor), que podemos definir como aquel ser humano, o grupo de seres humanos, con relaciones sociales y con capacidad para tomar decisiones; por lo que podemos hablar de agente individual (un ser humano) y agente colectivo (un grupo de seres humanos: familia, empresa, asociación, gobierno, partido político, sindicato, organismo supranacional...).

En la medida en que todos los sistemas sociales están formados por agentes, éstos son los responsables últimos tanto de las perturbaciones internas como de la regulación de dicho sistema; por tanto, por lo que a la regulación se refiere, si un sistema social puede ser regulado por los seres humanos que lo forman en virtud de su capacidad de tomar decisiones, estaremos ante un sistema autónomo o autorregulado. La autorregulación de los sistemas sociales descansa por tanto en la voluntad de los agentes (la causa no causada); por ello, la autorregulación de un sistema social resulta, a priori, indeterminada.

No obstante, dicha indeterminación es sólo parcial, debido a que podemos observar unas ciertas regularidades en las decisiones de los distintos agentes; siguiendo el principio de indeterminación parcial, no hay posibilidad de que en un momento dado pueda ocurrir literalmente cualquier cosa, sino que existe la posibilidad de que ocurran varias cosas y al final ocurre una de ellas.

Las regularidades de las decisiones de los distintos agentes reposan en el hecho de que los mismos viven en sociedad y, como consecuencia, presentan conductas culturales (8); dicho de otro modo, las decisiones de los agentes vienen condicionadas por la cultura en la que se encuentran inmersos; luego, desde la perspectiva del observador, las acciones de los agentes estarán parcialmente determinadas, por su cultura, y parcialmente indeterminadas, por su voluntad. El comportamiento de los agentes tiene así facetas deliberadas (decisiones) y facetas no deliberadas (hábitos).

Las decisiones de los agentes suponen que éstos pueden actuar en función de una variedad de formas posibles y que pueden cambiar de objetivos sin que exista un estímulo externo, por lo que la decisión es real y en ella se manifiesta la voluntad de los mismos. Sin embargo, los agentes tienen poderes de imaginación y de creatividad limitados por su propia experiencia y por los hábitos de pensamiento propios de la cultura a la que pertenecen. Por tanto, la indeterminación real, fruto de la voluntad, queda restringida por la cultura y el conjunto de posibilidades de decisión de los agentes queda limitado.

Dichas limitaciones vienen marcadas por las instituciones, que son aquellas normas y pautas de comportamiento comúnmente aceptados por los agentes del sistema social. Dichas instituciones son el resultado de decisiones pasadas de los agentes y constituyen decisiones a priori frente a las decisiones ipso facto ante un dilema; por ello, desde esta perspectiva, las instituciones son limitaciones para dichos agentes. 
Si la institución es una norma estaríamos ante limitaciones formales, mientras que si la institución es una pauta de comportamiento estaríamos ante limitaciones informales de los agentes.

Pero no todas las decisiones de los agentes que forman parte de un sistema social, ni todas las instituciones del mismo, tienen la finalidad de regularlo. Los motivos que generan las diferentes decisiones de los agentes, y que generaron en el pasado las instituciones que existen en un momento dado en un sistema social, son de naturaleza muy diferente y sólo algunas de las innumerables decisiones e instituciones van dirigidas a la regulación del mismo; serían las decisiones reguladoras y las instituciones reguladoras. Y los agentes que toman decisiones reguladoras serían los agentes reguladores.

Tanto las instituciones reguladoras como los agentes reguladores constituyen los mecanismos de autorregulación del sistema social; las primeras serían mecanismos de autorregulación automática (9) del sistema y los segundos mecanismos de autorregulación deliberada del sistema.

Pero como ya hemos afirmado, las decisiones de los agentes reguladores se encuentran condicionadas por la cultura en la que éstos se encuentran inmersos; en concreto, lo que condiciona dichas decisiones es una manifestación específica de la cultura, la ideología. Y por ideología entendemos el conjunto coherente de ideas y valores referidos a la regulación del sistema social y cuya función es guiar los comportamientos (decisiones y hábitos) de los agentes.

La manera que tienen los diferentes agentes de participar en la regulación de un sistema social es ejerciendo el poder; entendiendo por ejercicio del poder la ejecución de determinadas acciones por parte de un agente de forma tal que otros agentes se comporten por sí mismos de un modo distinto de como lo hubiesen hecho de otra forma; dichas acciones pueden ser deliberadas (decisiones) o no deliberadas (hábitos). Un agente será así más poderoso cuanto mayor sea la capacidad para que la regulación del sistema social al que pertenece se aproxime a sus intereses por medio de la modificación de las conductas de otros agentes.

Teniendo todo esto en cuenta, la autorregulación de un sistema social tiene lugar cuando una perturbación procedente del exterior o del interior del propio sistema es neutralizada, impidiendo con ello que el sistema se vuelva inestable. Si la perturbación ha sido prevista, lo habitual es que los agentes reguladores hayan creado una institución para responder a ella, por medio de una decisión a priori, de manera que, ante la citada perturbación, los diferentes agentes reaccionan de manera adaptativa automáticamente con un comportamiento preestablecido (institución) que evita la inestabilidad del sistema. Si la perturbación no ha sido prevista, lo habitual es que los agentes reguladores reaccionen tomando decisiones ipso facto para que el comportamiento de los diferentes agentes se adapten a la nueva situación sin poner en peligro la estabilidad del sistema.

El propósito, por tanto, de la autorregulación de un sistema social es garantizar la estabilidad del mismo adaptándose a los cambios. Ahora bien si los mecanismos de autorregulación fallan y el sistema social no es capaz de adaptarse a los cambios, éste entrará en un período de inestabilidad, denominado crisis, caracterizado por una gran incertidumbre sobre el devenir futuro de dicho sistema, y que podría desembocar, en peor de los casos, en la pérdida de identidad del sistema y en su desintegración como entidad. 
4.2. La regulación del sistema económico mundial: la gobernanza global

El sistema económico mundial, como sistema social autónomo, tiene la capacidad de autorregularse siguiendo las mismas pautas que el resto de los sistemas sociales; es decir, trata de garantizar su propia estabilidad neutralizando las perturbaciones que procedan del medio ambiente (por ejemplo, el cambio climático), de los sistemas de su entorno (por ejemplo, las migraciones de balseros cubanos) o del propio interior del sistema mundial (por ejemplo, la depreciación del dólar).

Para ello se ponen en funcionamiento, en primer lugar, los mecanismos de autorregulación automática, es decir, las instituciones (por ejemplo, el Protocolo de Kyoto, las leyes migratorias y la solidaridad de la sociedad civil de EEUU o el aumento de las exportaciones de EEUU y los países vinculados al dólar, por seguir con los ejemplos anteriores) que tratarán que las perturbaciones no afecten a la estabilidad del sistema. Si dichas instituciones no tienen éxito, entonces entrarán en funcionamiento los mecanismos de autorregulación deliberada del sistema económico mundial, es decir, los agentes, que tomarán decisiones con intención de neutralizar las perturbaciones (por ejemplo, los grupos ecologistas que presionan para que se cumpla el Protocolo de Kyoto, la Secretaría de Estado de EEUU que presiona al gobierno cubano para que impida la salida de más balseros o los gobernadores de los bancos centrales del G-8 que se reúnen para determinar si deben comprar dólares en los mercados de divisas, por seguir con los ejemplos anteriores).

Al no existir un agente regulador principal, como podría ser un gobierno mundial, el poder es ejercido por innumerables agentes, que serán más poderosos en la medida en que sus acciones (deliberadas y no deliberadas) sean capaces de condicionar las acciones de otros agentes, consiguiendo con ello que la regulación del sistema económico mundial se aproxime a sus intereses; es decir, el poder en el sistema económico mundial es un poder difuso que no se concentra en un agente en concreto.

Así, en función del ejercicio del poder, podemos identificar dos tipos de agentes reguladores: los directos, cuyas acciones deliberadas condicionan las acciones reguladoras de la mayoría de los agentes; y los indirectos, cuyas acciones deliberadas condicionan las acciones de los agentes reguladores directos. Así, las acciones deliberadas de un agente regulador indirecto condicionan las acciones deliberadas de un agente regulador directo, cuyas acciones, a su vez, condicionan las acciones reguladoras de la mayoría de los agentes, incluido el agente regulador indirecto cuyas acciones deliberadas condicionaron las acciones deliberadas del agente regulador directo; con lo que tenemos que el ejercicio del poder no solamente se encuentra difuso, sino que también tiene un carácter recursivo (10).

Entre los agentes reguladores directos del sistema económico mundial podríamos destacar todos los organismos internacionales del Sistema de Naciones Unidas, el G-8 (o Grupo de los Ocho) y los gobiernos de las grandes potencias económicas. Mientras que entre los agentes reguladores indirectos tendríamos todo tipo de organizaciones trasnacionales (OPEP, OCDE, Comisión Trilateral, Foro Económico Mundial, Foro Social Mundial, movimientos sociales alternativos, empresas transnacionales...), los gobiernos del resto de los países, todo tipo de organizaciones de ámbito nacional, regional o local, e incluso individuos concretos (líderes de opinión, votantes...).

La interacción de todos estos agentes reguladores directos e indirectos es la que permite la regulación del sistema económico mundial. Pero, tal vez, lo más significativo de ello sea que los gobiernos no son 
claramente los únicos agentes que se preocupan por la citada regulación, sino que dicha interacción tiene una dimensión gubernamental (o pública), una dimensión empresarial (o privada) y una dimensión social (o civil).

Este hecho supone un cambio significativo respecto de la regulación de las relaciones económicas internacionales, es decir, entre sistemas económicos capitalistas nacionales previas a la aparición del sistema económico mundial; en este caso, al tratarse de relaciones entre naciones, los gobiernos nacionales como agentes reguladores principales de dichos sistemas jugaban un papel protagonista en la citada regulación, a la que se denominaban Orden Económico Internacional. Sin embargo, al pasar las relaciones económicas internacionales a ser relaciones endógenas o internas del sistema económico mundial, éstas son ahora reguladas por los mecanismos de regulación de dicho sistema, en los que los gobiernos nacionales comparten el protagonismo con otros agentes públicos, privados y civiles; esto ha hecho surgir un nuevo término para referirse a la regulación del sistema económico mundial, la gobernanza global o más estrictamente la gobernanza económica global o la gobernanza de la economía mundial (11). Por tanto, podemos entender la gobernanza global, en su dimensión económica, como sinónimo de la autorregulación del sistema económico mundial.

4.3. La ideología dominante en la regulación del sistema económico mundial: el neoliberalismo

Actualmente, la ideología dominante entre los agentes reguladores del sistema económico mundiales es el neoliberalismo, que vino a sustituir al keynesianismo imperante entre los agentes reguladores de los sistemas económicos capitalistas nacionales entre la Segunda Guerra Mundial y la crisis de dichos sistemas de los años setenta.

El neoliberalismo puede definirse como aquella ideología que tiene como fundamento la mínima intervención del Estado y la máxima libertad de los agentes que intervienen en los mercados. Dicha ideología inspira no sólo la mayoría de las decisiones de los agentes reguladores, sino que también ha inspirado la mayoría de las actuales instituciones reguladoras y, mientras no se produzca un cambio ideológico, seguirá inspirando tanto las instituciones como las decisiones reguladoras; por lo tanto, la actual regulación del sistema económico mundial reposa en el neoliberalismo.

El neoliberalismo, como ideología, consiste en una serie de ideas y valores concernientes a la regulación de los sistemas económicos capitalistas y, por tanto, a la del sistema económico mundial.

Para los neoliberales, el fin último del funcionamiento del sistema económico mundial (como el de todo sistema económico capitalista), ha de ser la satisfacción de las necesidades del individuo singular y no la satisfacción de las necesidades de la abstracción que es la sociedad; por ello, lo individual no debe ser sacrificado en aras de lo colectivo.

Dicho fin viene garantizado por tres valores considerados como derechos naturales del individuo: la libertad de elegir, la justicia social y la propiedad privada.

a) La libertad de elegir. Todo individuo tiene derecho a poder elegir en todo aquello relacionado con la satisfacción de sus necesidades, y no debe ser privado de este derecho por ninguna creencia, ya sea religiosa o ideológica, que le obligue a actuar en contra de sus propios intereses. Pero un individuo no tendrá libertad 
de elegir si no existen ni la igualdad de oportunidades que garantiza la justicia social, ni el derecho a la propiedad privada.

b) La igualdad de oportunidades. Todo individuo tiene derecho a recibir un trato socialmente justo en todo aquello relacionado con la satisfacción de sus necesidades, entendiendo por justicia social la igualdad de oportunidades y no el igualitarismo; es decir, todo individuo tiene derecho a que se le garantice el mismo punto de partida en su tarea de satisfacer sus necesidades, pero no el mismo punto de llegada (la misma renta, la misma riqueza o la misma posición social), dado que lo que obtenga un individuo ha de ser el resultado de su esfuerzo y sacrificio elegido en libertad. Pero no habrá justicia social si el individuo no tiene libertad para elegir ni derecho a la propiedad privada.

c) La propiedad privada. Todo individuo tiene derecho a poseer en exclusiva aquellos bienes materiales que ha conseguido con su esfuerzo como medio para satisfacer sus necesidades, sin que pueda ser privado de ello por la acción de otros individuos o de los Estados. Pero para que un individuo pueda ejercer plenamente el derecho de propiedad privada, es preciso que él mismo tenga libertad de elegir y disfrute de justicia social.

Mientras el derecho de propiedad privada se sustenta en el imperio de la ley y en el funcionamiento de la justicia, los otros dos valores, la libertad de elegir y la justicia social, están sustentados por dos ideas-fuerza:

a) El libre mercado con Estados mínimos. La libertad de elegir de un individuo se materializa en un mercado libre en el que los Estados de los países tengan la menor intervención posible. Siempre que no esté intervenido, el mercado es el mejor mecanismo para asignar eficientemente los recursos escasos entre usos alternativos al objeto de satisfacer las necesidades de los individuos; y ninguna organización, por sofisticada que sea, incluidos los Estados de los países, puede sustituir la voluntad colectiva de los individuos que se manifiesta en el mercado. Si los Estados intervienen en los mercados con intención de variar los resultados de los mismos, falsean la voluntad de los individuos y ello desencadena reacciones individuales que terminan por bloquear la acción estatal, además de generar una asignación no eficiente de los recursos con el resultado de un menor crecimiento económico. Además, cuanto más grandes son los Estados de los países más débiles, más corruptos y menos eficaces son; lo cual no significa que éstos no deban existir; sino todo lo contrario; los Estados han de ser fuertes, pero pequeños, encargados de hacer cumplir las leyes y de prestar los servicios que les son inherentes, como el de justicia y el de orden público. Los Estados de los países deben adelgazar, ya que ésta es la vía más rápida para tecnificarlos y moralizarlos, lo que al mismo tiempo permite devolver a la iniciativa privada responsabilidades y tareas como la creación de riqueza o la provisión de seguridad social. Los individuos deben aprender a vivir sin el paternalismo de los Estados, haciendo uso de su libertad y responsabilizándose de sus propios futuros.

b) El crecimiento económico con efecto goteo. La igualdad de oportunidades a la hora de satisfacer las necesidades de los individuos viene respaldada por derramamiento de los frutos del crecimiento económico sobre los individuos. Las políticas que favorecen el crecimiento, generalmente, benefician más a los pobres que aquellas políticas que favorecen la distribución. Cuando la intervención del Estado trata de modificar la distribución de la renta originada por el mercado, además de ir en contra de la justicia social, genera una serie de distorsiones en el mercado que impiden que éste asigne eficientemente los recursos, por lo que a medio plazo la economía deja de crecer y los sectores populares terminan por ser los más perjudicados. Sin embargo, si el Estado se limita a favorecer que la iniciativa privada pueda crear riqueza, generando así un crecimiento económico significativo, los propios mecanismos del mercado derramarán esa riqueza entre 
todos los agentes económicos (efecto trickle-down o goteo), tanto por la vía del aumento del empleo y de los beneficios empresariales, como por la del abaratamiento del consumo gracias a la libre competencia; $y$ esto termina beneficiando a todos los individuos.

Ambas ideas-fuerza aparecen vinculadas por la tesis de la competitividad, según la cual el crecimiento económico es el resultado del afán de empresas y países por ser competitivos. Se entiende por competitividad la capacidad que tienen los productos de una empresa o de un país para ser demandados con preferencia frente a productos similares de otras empresas o países. Un producto sólo puede ser competitivo si está sometido a las condiciones del libre mercado; si los Estados no intervienen protegiendo o beneficiando los productos de ciertos países, ciertas empresas (o ciertos sectores) mediante regulaciones, entonces sólo aquellos productos que satisfagan las necesidades de calidad y precio exigidas por el mercado podrán sobrevivir. Por tanto, el primer requisito para que la producción de un país o de una empresa sea competitiva es que no existan distorsiones que impidan el funcionamiento del libre mercado, ya sean estas distorsiones barreras proteccionistas o regulaciones internas, o ya afecten a los mercados de productos o a los mercados de factores.

La bondad de esta tesis reposa en la aplicación de una serie de políticas económicas articuladas en cuatro ejes: la estabilización macroeconómica y la liberalización de los mercados de productos (liberalización comercial) y de factores (liberalización financiera y laboral).

a) La estabilización macroeconómica. El primer paso para que los productos de una empresa o un país puedan competir en los mercados es que éstos funcionen con el menor grado de incertidumbre posible. El crecimiento económico basado en la iniciativa privada está muy influido por las expectativas de los distintos agentes económicos, que deben tomar decisiones de consumo, ahorro, inversión, contratación, etc. Cuanto mayor sea la estabilidad macroeconómica menor será la incertidumbre, las decisiones podrán tomarse con mayor seguridad y las expectativas serán favorables a la expansión de los negocios y, consecuentemente, de la producción y del empleo. Variables como la inflación, el tipo de interés, el tipo de cambio, los déficit público y de la balanza por cuenta corriente, las deudas interna y externa, se convierten en variables estratégicas que deben ser controladas por los Estados de forma que se garantice su estabilidad para que así los agentes económicos tomen decisiones en un entorno de incertidumbre baja.

b) La liberalización comercial. El segundo paso para que los productos de una empresa o un país puedan competir en los mercados es que éstos tengan el menor grado de intervención posible, lo que significa la eliminación tanto de las regulaciones de los mercados nacionales como de las barreras proteccionistas que puedan existir. Para que los productos de un país sean demandados por otros países es preciso que dichos productos sean competitivos, y ello no es posible si las empresas de dicho país tienen su producción defendida por una estructura arancelaria proteccionista, que termina generando un sesgo anti-exportador; por ello, si se eliminan todas aquellas trabas que dificultan el libre comercio, las empresas del país tendrán que enfrentar el reto de la competitividad y especializarse en aquellas actividades para las que dispongan de ventajas competitivas, abandonando así las actividades para las que no existen dichas ventajas. La demanda exterior se concentrará en aquellas producciones competitivas, estimulando así el crecimiento económico, mientras que los productos competitivos procedentes del exterior entrarán en el mercado interno, con los consecuentes beneficios en menores precios y mayor variedad de productos para elegir.

c) La liberalización financiera. El tercer paso para que los productos de una empresa o un país puedan competir en los mercados es que los productores tengan acceso a los capitales necesarios para producirlos. 
Los mercados financieros habrán de ser igualmente libres, ya que así la asignación de los recursos financieros será más eficiente; dicha libertad supondría también la apertura de la cuenta de capitales de las balanzas de pago, de manera que pueda entrar y salir ahorro de los diferentes países en busca de las mejores oportunidades de inversión. Así, la libertad de movimientos de capitales entre países permite la entrada del capital extranjero allí donde es necesario, en forma de inversión extranjera directa o en forma de inversión extranjera de cartera.

d) La liberalización laboral. El cuarto paso para que los productos de una empresa o un país puedan competir en los mercados es que los productores tengan acceso a toda la mano de obra necesaria para producirlos. Las decisiones productivas de los productores también están influidas por las condiciones de la contratación laboral, siendo el mercado de trabajo uno de los que concentra mayores distorsiones. La actuación paternalista de los Estados, en unas ocasiones, y la acción corporativa de los sindicatos, en otras, han llenado dicho mercado de rigideces que impiden una rápida y poco costosa adaptación de la contratación a las necesidades de la producción. El reto de la competitividad exige, por un lado, moderación salarial para poder competir vía precios y, por otro, plantillas flexibles que permitan adaptar la producción a las fluctuaciones de la demanda. Además los movimientos migratorios entre países permiten la entrada de mano de obra extranjera allí donde es necesaria.

Así, el neoliberalismo como ideología inspira decisiones reguladoras de los agentes y las instituciones reguladoras del sistema económico mundial; y mientras éstas y aquéllas sean capaces de permitir la adaptación del sistema económico mundial a los cambios ambientales, los cambios de los sistemas de su entorno o los cambios internos, y de mantener así la identidad capitalista de dicho sistema, el neoliberalismo seguirá siendo la ideología dominante. Sin embargo, en el momento en el que los citados mecanismos de autorregulación fracasen en la adaptación del sistema económico mundial a la nueva situación, o bien se producirá un cambio ideológico en los agentes reguladores del sistema económico mundial o bien dicho sistema perderá su identidad capitalista y se desintegrará como tal.

De hecho, algunos analistas consideran que la aparición en Estados Unidos de las hipotecas "subprime”, y de toda la ingeniería financiera derivada de ellas, fue una perturbación, o cambio interno del sistema, que no pudo ser neutralizada por los mecanismos de regulación del mismo, generando así una crisis financiera mundial que comenzó en 2007 y que habría provocado un cambio ideológico en los agentes reguladores del sistema económico mundial; hecho que se habría puesto de manifiesto tanto en las nacionalizaciones y las intervenciones de rescate de entidades financieras de Estados Unidos y la Unión Europea, como las actuaciones de los bancos centrales del G-7 (12) y del Eurogrupo (13). Sin embargo, la constatación de dicho cambio ideológico requiere de la existencia de más medidas que pongan de manifiesto el abandono del neoliberalismo y no sólo la existencia de algunas excepciones a la aplicación del mismo; sólo el paso del tiempo dirá si estamos ante un cambio ideológico.

\section{Notas}

(1) Cuentan los cronistas de Indias, en relación con la conquista de México (aunque esto podría ser una realidad construida), que la primera vez que los nativos americanos vieron a los soldados españoles montados a caballo, al no tener experiencia perceptiva previa de ningún caballo, distinguieron unas unidades a las que atribuyeron características sobre-humanas; sin embargo, a medida que su experiencia perceptiva fue aumentado, al ver a los soldados bajar de sus monturas, su capacidad de distinción mejoró. 
(2) Una de las características de las relaciones económicas es que no es necesaria la simultaneidad espaciotemporal de los seres humanos que mantienen una relación entre sí, ya que parte de las mismas se mantienen por la intermediación de un bien o de un medio de pago. Así, un ser humano puede consumir un bien que ha sido producido por otro ser humano que vivió en otro lugar y en otro tiempo; sería el caso del violinista que usa su violín Stradivarius, manteniendo con ello una relación económica con Antonius Stradivarius que vivió entre 1644 y 1737.

(3) 0 sistema económico tributario.

(4) Existen otras muchas características de estos tipos de organización, como por ejemplo las institucionales y las tecnológicas, pero consideramos que las cuatro señaladas nos sirven al objeto de definirlos.

(5) Entendemos por instituciones aquellas normas o pautas de comportamiento generalmente aceptadas por los individuos de una sociedad.

(6) Se entiende que los océanos son surcados por barcos en los habitan seres humanos y que en parte de los desiertos y las zonas polares habitan seres humanos pertenecientes a sociedades como los Tuareg y los Inuit.

(7) Una subdisciplina que realiza lo anterior es la antropología económica, por ejemplo.

(8) Las conductas culturales, transmitidas entre generaciones, tuvieron, en algún momento, su origen en una decisión; su transmisión es fruto, de nuevo, de una decisión, así como su aceptación. En última instancia, las conductas culturales son fruto de la voluntad.

(9) "Automática" en la medida en que la decisión es previa al acontecimiento sobre el que se debe decidir (a priori) y funciona a modo de regla, eliminando la posibilidad de una decisión ipso facto.

(10) Algo es "recursivo" si se define en términos de sí mismo.

(11) En un sentido estricto la gobernanza global englobaría la regulación de aspectos ajenos al ámbito de los fenómenos económicos (por ejemplo, el terrorismo).

(12) G-8 menos Rusia.

(13) Grupo de países de la Unión Europea pertenecientes a la zona euro.

\section{Bibliografía}

Bertalanffy, L. von. 1976. Teoría General de los Sistemas. México: Fondo de Cultura Económica.

Hidalgo Capitán, A.L. 2007. El sistema económico mundial y la gobernanza global. Una teoría de la autorregulación de la economía mundial. Málaga: Eumed.net, edición electrónica gratuita disponible en línea en http://eumed.net/libros/2007b/280/indice.htm.

Maturana, H. 1995. La realidad: ¿objetiva o construida? I Fundamentos biológicos de la realidad. Barcelona: Anthropos.

Maturana, H. 1996. La realidad: ¿objetiva o construida? II Fundamentos biológicos del conocimiento. Barcelona: Anthropos.

North, D. C. 1993. Instituciones, cambio institucional y desempeño económico. México: Fondo de Cultura Económico.

Strange, S. 2001. La retirada del Estado: la difusión del poder en la economía mundial. Barcelona: Icaria INTERMON.

Varela, F. J., Thompson, E. y Rosch, E. 1992. De cuerpo presente. Las ciencias cognitivas y la experiencia humana. Barcelona: Gedisa.

Recibido el 15 Mar 2009

Aceptado el 24 Nov 2009 